\title{
Feasibility of Total Variation Noise Reduction Algorithm According to Various MR-Based PET Images in a Simultaneous PET/MR System: A Phantom Study
}

\author{
Chan-Rok Park ${ }^{1}$ (), Seong-Hyeon Kang ${ }^{2}$ and Young-Jin Lee ${ }^{2, *}$ \\ 1 Department of Radiological Science, Jeonju University, 303, Cheonjam-ro, Wansan-gu, Jeonju-si, \\ Jeollabuk-do 55069, Korea; tigeaglepcr@jj.ac.kr \\ 2 Department of Radiological Science, Gachon University, 191, Hambakmoero, Yeonsu-gu, \\ Incheon 21936, Korea; tjdgus7345@nate.com \\ * Correspondence: yj20@gachon.ac.kr; Tel.: +82-32-820-4362
}

check for

updates

Citation: Park, C.-R.; Kang, S.-H.; Lee, Y.-J. Feasibility of Total Variation Noise Reduction Algorithm

According to Various MR-Based PET Images in a Simultaneous PET/MR System: A Phantom Study.

Diagnostics 2021, 11, 319.

https://doi.org/10.3390/

diagnostics11020319

Academic Editor: Elina A. Genina

Received: 7 January 2021

Accepted: 15 February 2021

Published: 16 February 2021

Publisher's Note: MDPI stays neutral with regard to jurisdictional claims in published maps and institutional affiliations.

Copyright: (c) 2021 by the authors. Licensee MDPI, Basel, Switzerland. This article is an open access article distributed under the terms and conditions of the Creative Commons Attribution (CC BY) license (https:/ / creativecommons.org/licenses/by/ $4.0 /)$.

\begin{abstract}
Recently, the total variation (TV) algorithm has been used for noise reduction distribution in degraded nuclear medicine images. To acquire positron emission tomography (PET) to correct the attenuation region in the PET/magnetic resonance (MR) system, the MR Dixon pulse sequence, which is based on controlled aliasing in parallel imaging, results from higher acceleration (CAIPI;

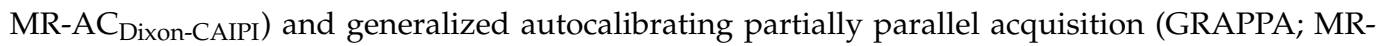
$A C_{\text {Dixon-GRAPPA }}$ ) algorithms are used. Therefore, this study aimed to evaluate the image performance of the TV noise reduction algorithm for PET/MR images using the Jaszczak phantom by injecting ${ }^{18} \mathrm{~F}$ radioisotopes with PET/MR, which is called mMR (Siemens, Germany), compared with conventional noise-reduction techniques such as Wiener and median filters. The contrast-to-noise (CNR) and coefficient of variation (COV) were used for quantitative analysis. Based on the results, PET images with the TV algorithm were improved by approximately $7.6 \%$ for CNR and decreased by approximately $20.0 \%$ for COV compared with conventional noise-reduction techniques. In particular, the image quality for the MR-AC $C_{\text {Dixon-CAIPI }}$ PET image was better than that of the MR-AC Dixon-GRAPPA $_{\text {PET }}$ image. In conclusion, the TV noise-reduction algorithm is efficient for improving the PET image quality in PET/MR systems.
\end{abstract}

Keywords: positron emission tomography (PET)/magnetic resonance (MR); total variation (TV); noise-reduction algorithm; attenuation correction; nuclear medicine

\section{Introduction}

Medical imaging in nuclear medicine plays an important role in acquiring functional information about patients using positron emission tomography (PET) with various radioisotopes [1,2]. In addition, the development of hybrid scanners, that is, PET/computed tomography (CT) or PET/magnetic resonance (MR), is helpful in obtaining functional and anatomic information simultaneously. Integrated PET/MR images have advantages over PET/CT images with respect to the reduction of radiation exposure and superior soft-tissue imaging $[3,4]$.

Originally, a PET/MR scanner was developed by separating PET and MR based on sequential imaging because the magnetic fields use in MR distort the gamma signal [5]. Furthermore, the MR magnetic field can interrupt the normal operation of the photomultiplier tube (PMT) and cause artifacts related to eddy currents [6,7]. However, integrated PET/MR, which combines both PET and MR scanners, has been achieved by replacing the PMTs with avalanche photodiodes (APDs) [8,9]. In addition, PET and MR scans are available simultaneously. Torigian et al. reported that integrated PET/MR imaging is more powerful than PET, PET/CT, or MRI alone [10].

The principle of gamma-ray detection in PET is that two annihilation radiations produced between positrons and electrons are detected by a scintillation detector [11]. 
However, signal loss occurs during the process of gamma ray detection because of attenuation or scattering effects. To overcome this problem, attenuation correction (AC) for $\mathrm{PET} / \mathrm{CT}$, which is called CT-based PET imaging, is performed by applying a suitable AC coefficient using the Hounsfield unit value at $511 \mathrm{keV}[12,13]$. In PET/MR, AC is performed by applying various MR pulse sequences. In general, the Dixon pulse sequence is applied to the $\mathrm{AC}\left(\mathrm{MR}-\mathrm{AC}_{\text {Dixon }}\right)$ [14-20]. The $\mathrm{MR}-\mathrm{AC} \mathrm{C}_{\text {Dixon }}$ pulse sequence assigns the attenuation coefficient to soft tissue by dividing it into four categories: background, fat, lungs, and soft tissue [14,15]. To improve the image quality of MR-based PET images based on the

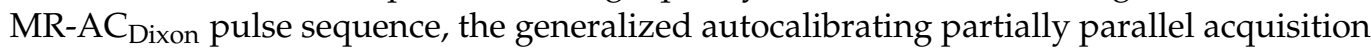

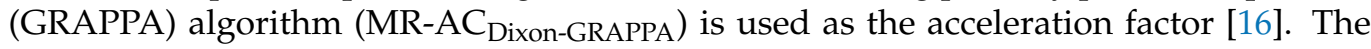
MR-AC $C_{\text {Dixon-GRAPPA }}$ pulse sequence accelerates the acquisition of MR data by acquiring several k-space values and compensating them to approximate values to achieve a short acquisition time [17]. In addition, the MR-AC $C_{\text {Dixon-GRAPPA }}$ pulse sequence is expanded by applying controlled aliasing in parallel imaging, resulting in a higher acceleration (CAIPIRINHA) algorithm (MR-AC Dixon-GAIPI $_{\text {[ }}$ [18]. The MR-AC Dixon-GAIPI $_{\text {pulse sequence features }}$ a high resolution for breath-hold MR imaging because of the shorter acquisition time

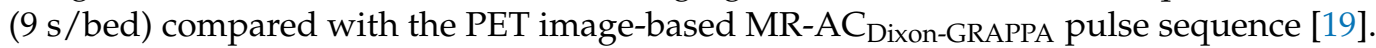
Consequently, the $\mathrm{AC}$ process using various $\mathrm{MR}-\mathrm{AC}$ pulse sequences $\left(\mathrm{MR}-\mathrm{AC} \mathrm{C}_{\text {Dixon-GRAPPA }}\right.$ and $\mathrm{MR}-\mathrm{AC}_{\text {Dixon-GAIPI }}$ ) is necessary to improve the PET image quality.

In addition, noise occurs in nuclear medicine images because of a poor photon count [21]. To solve this problem, there is a technique to increase the number of photons by injecting high radioactivity, but the patient receives a lot of radiation exposure. Therefore, many researchers have proposed noise-reduction algorithms without increasing the radiation exposure [22-24]. Wiener and median filters are widely used as conventional filters to reduce noise distribution in degraded images. The degree of noise reduction is effective, but a blurring effect is caused by the loss of high-frequency and edge signals in the images $[25,26]$. To overcome this drawback, a total variation (TV) algorithm that is able to maintain the edge signal and reduce the noise distribution by setting the region of interest for each pixel in the image has been suggested [27,28]. The TV noise reduction algorithm has already been proven using radiologic images from X-rays [29]. In particular, a study by Kang et al. reported that CNR and COV were significantly improved in all three planes compared with the original image when the TV algorithm was applied to a 4D small-animal CT image [27]. In addition, research by Seo K. et al. confirmed that the TV algorithm greatly improved the image characteristics in the noise distribution in the frequency domain in X-ray images [29]. Recently, a study on the applicability of the TV algorithm to confocal laser scanning microscopy images was also conducted, and a quantitative analysis method of noise level for two color channels was also proposed [30]. However, there is little research in the nuclear medicine field, especially PET/MR images, that has been recently developed.

Therefore, the purpose of this study was to confirm the effectiveness of the TV noisereduction algorithm for PET/MR images. To evaluate the image performance, images were acquired by applying various MR-AC pulse sequences (MR-AC Dixon-GRAPPA $_{\text {and }}$ MR-AC Dixon-GAIPI $)$ to PET images with a TV noise-reduction algorithm and compared with conventional techniques such as Wiener and median filters.

\section{Materials and Methods}

\subsection{Experimental Setup}

The integrated PET/MR hybrid system, which is called mMR (Siemens, München, Germany), was used for the phantom experiments. Figure 1 shows the PET/MR scanner and Jaszczak phantom, which contains rods of various diameters. 


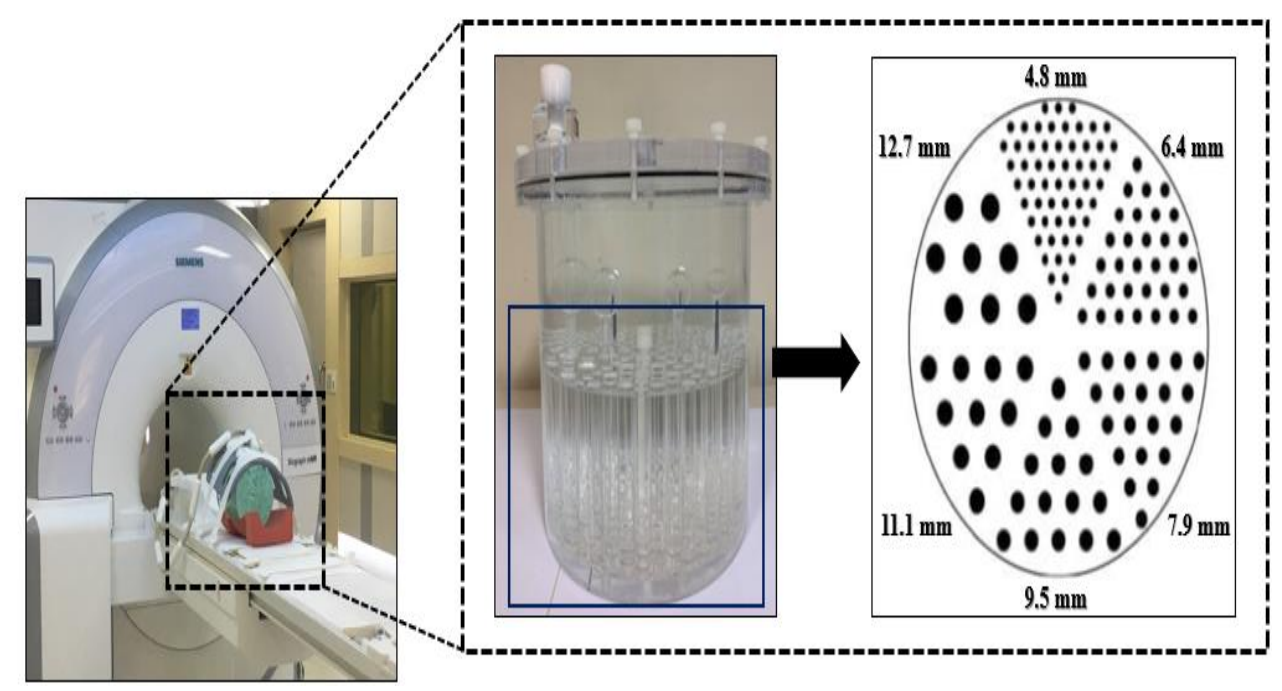

Figure 1. Experimental setup using a positron emission tomography (PET)/magnetic resonance (MR) scanner and a Jaszczak phantom.

The detector used lutetium oxyorthosilicate material as a scintillator crystal in PET/MR with an avalanche photodiode array system. To acquire various MR-based PET images, $\mathrm{MR}_{\text {Dixon-CAIPI }}$ and $\mathrm{MR}_{\text {Dixon-GRAPPA }}$ pulse sequences were applied to non-AC PET images using a phantom injected with $\mathrm{NiSO}_{4}+\mathrm{NaCl}$ fluids to acquire more uniform MR-based PET images than MR-based PET images using only water fluid. In general, the water is used as phantom fluid when obtaining the phantom images in nuclear medicine because the radioisotope ${ }^{18} \mathrm{~F}$ dissolves in water. However, water causes artifacts in MR imaging above $1.5 \mathrm{~T}$ due to high relative permittivity [31]. Figure 2 shows a schematic diagram of this study. In this study, the partial-volume effect, which is the loss of apparent activity in small spheres caused by a limited imaging system, is considered using the mMR imaging system.

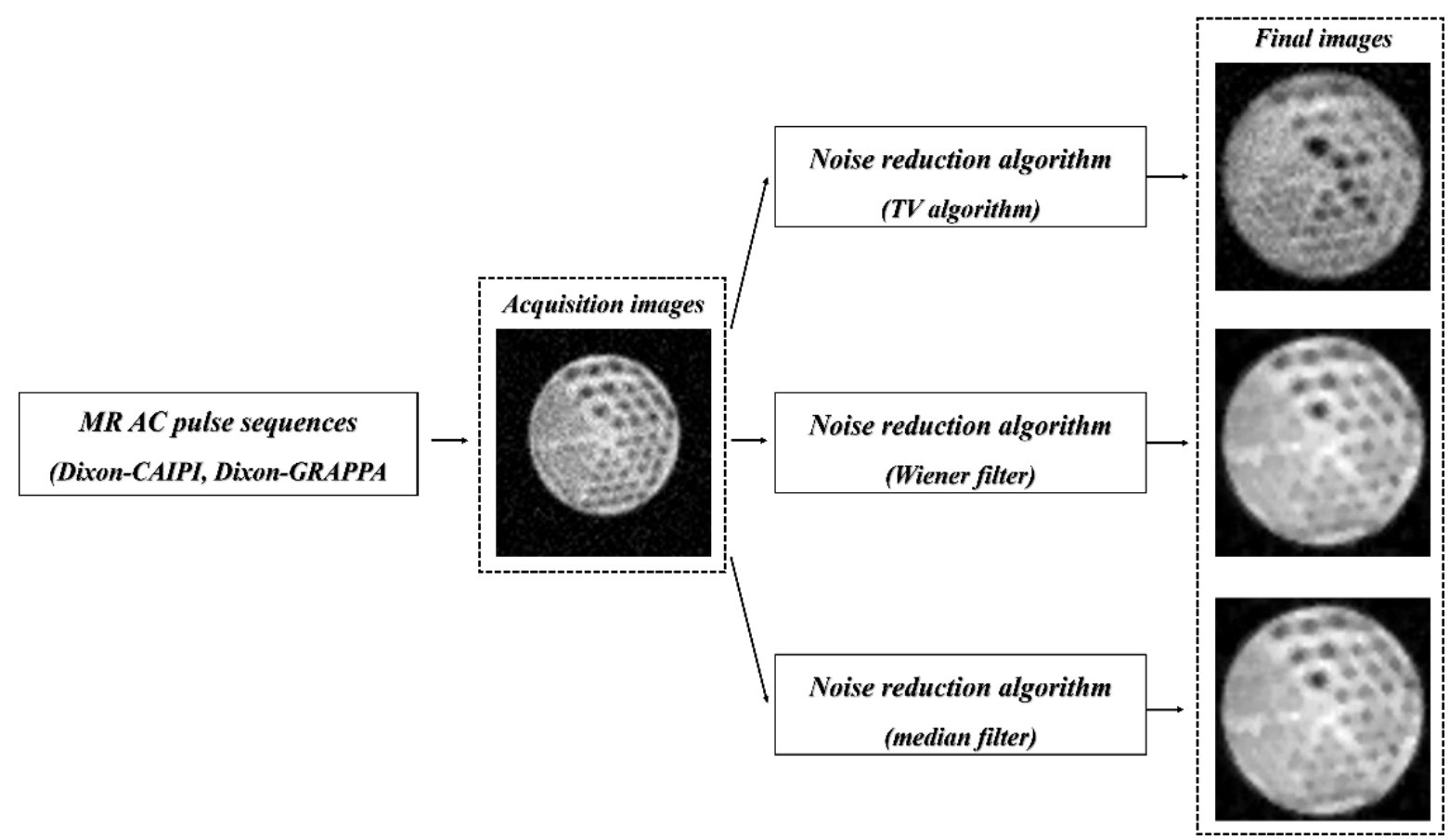

Figure 2. Flowchart for acquisition of images applied to $\mathrm{MR}_{\text {Dixon-CAIPI }}$ and $M R_{\text {Dixon-GRAPPA }} A C$ pulse sequences to final images using the total variation (TV) algorithm, Wiener filter, and median filter for noise reduction. 


\subsection{Modeling of the TV Noise-Reduction Algorithm}

Gaussian noise, which is generated in various medical-imaging systems based on gamma rays and $\mathrm{X}$-rays, should be removed because it degrades the image quality and affects the efficiency of post-processing. To resolve the noise problem, various denoising methods have been proposed, such as local filters, wavelet transform-based techniques, and machine learning. Among these techniques, the TV-based algorithm is known to effectively remove Gaussian noise because it considers the correlation between the signal intensity of the region of interest (ROI) and the overall image configuration variance. The TV algorithm performs a gradient that calculates the difference between the pixel value of the ROI and the surrounding pixel value as follows:

$$
\begin{gathered}
|| f(m, n) \|_{T V}=\sum_{m=1}^{M} \sum_{n=1}^{N}|\nabla f(m, n)| \\
=\sum_{m=1}^{M} \sum_{n=1}^{N} \sqrt{(f(m, n)-f(m-1, n))^{2}+(f(m, n)-f(m, n-1))^{2}}
\end{gathered}
$$

where $\mathrm{M}$ and $\mathrm{N}$ are the numbers of rows and columns in the image $\mathrm{f}(\mathrm{m}, \mathrm{n})$, respectively, and $\nabla$ is the gradient operator. The L2-norm has the risk of incorrect image processing, which considers the noise to the edge signal, because it is sensitive to noise, although it is known to be an effective gradient operator for extracting edge signals. For this reason, we designed a gradient operator using the L1-norm. Based on Equation (1), an optimized Rudin-Osher-Fatemi (ROF) model was presented by Rudin et al. [28].

$$
\varphi[\mathrm{f}(\mathrm{m}, \mathrm{n}) \mid \mathrm{I}(\mathrm{m}, \mathrm{n})]=\sum_{\mathrm{m}=1}^{\mathrm{M}} \sum_{\mathrm{n}=1}^{\mathrm{N}}|\nabla \mathrm{f}(\mathrm{m}, \mathrm{n})|_{1}+\frac{\lambda}{2}|| \mathrm{I}(\mathrm{m}, \mathrm{n})-\mathrm{f}(\mathrm{m}, \mathrm{n}) \|_{2}
$$

where $\frac{\lambda}{2}\|I(m, n)-f(m, n)\|_{2}$ is the fidelity term indicating the accuracy of the image information, and $\sum_{\mathrm{m}=1}^{\mathrm{M}} \sum_{\mathrm{n}=1}^{\mathrm{N}}|\nabla \mathrm{f}(\mathrm{m}, \mathrm{n})|_{1}$ is a regularization term that assists the object function $(=\varphi[\mathrm{f}(\mathrm{m}, \mathrm{n}) \mid \mathrm{I}(\mathrm{m}, \mathrm{n})])$ in finding the correct solution. In addition, $\lambda$ is a control parameter that balances the two terms, and a value of 0.1 was applied in this study $[32,33]$. Based on Equation (2), a solution was obtained by iteratively calculating the weight for the pixel of the ROI and its surroundings. To compare the MR-based PET images in PET/MR with application of the TV algorithm, Wiener and median filters were used for correction of noisy images.

\subsection{Quantitative Analysis}

To evaluate image quality, the contrast-to-noise ratio (CNR) and coefficient of variation (COV) were used by drawing ROIs in images with noise, Wiener, median, and TV algorithms. The CNR and COV values were calculated as follows.

$$
\begin{gathered}
\mathrm{CNR}=\frac{\left|\mathrm{H}_{\mathrm{s}}-\mathrm{H}_{\mathrm{B}}\right|}{\sqrt{\sigma_{\mathrm{s}}^{2}+\sigma_{\mathrm{B}}^{2}}} \\
\mathrm{COV}=\frac{\sigma_{\mathrm{s}}}{\mathrm{H}_{\mathrm{s}}}
\end{gathered}
$$

where $\mathrm{H}_{\mathrm{S}}$ and $\sigma_{\mathrm{S}}$ are the mean count and standard deviation of the sphere ROI, respectively, and $\mathrm{H}_{B}$ and $\sigma_{B}$ are the mean count and standard deviation for the background ROI, respectively. The quantitative analysis method for COV is widely used to confirm noise distribution. In addition, the CNR is used to compare contrast between the sphere and background. For reproducibility analysis, we performed the experiment 10 times under the same conditions. 


\section{Results and Discussion}

The PET images based on the MR pulse sequences were developed using an integrated PET/MR system, and there have been many studies that attempted to improve PET image quality [34,35]. In previous studies, we confirmed the usefulness of the TV algorithm for noise reduction compared with conventional noise-reduction methods such as Wiener and median filters in X-ray based images and MR images [36,37]. The results of previous studies show that the TV algorithm not only resulted in efficient noise reduction, but also improvement in signal and contrast in medical images. Based on our previous studies, we evaluated the feasibility of the TV algorithm for noise reduction in $\mathrm{MR}-\mathrm{AC}_{\text {Dixon-CAIPI }^{-}}$

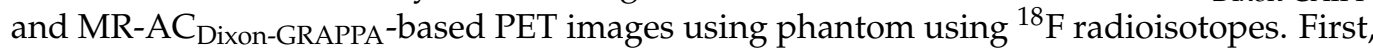
MR-AC PET images were acquired using MR-AC Dixon-CAIPI $_{\text {and } M R-A C_{\text {Dixon-GRAPPA }} \text { pulse }}$ sequences. Subsequently, Gaussian noise with a 0.001 variance parameter was applied to acquire the PET images using MATLAB software. To evaluate the image performance for noise reduction, the proposed TV algorithm was used for noise reduction and compared with conventional noise reduction filters.

Figures 3 and 4 show the MR-AC Dixon-CAIPI- and MR-AC $C_{\text {Dixon-GRAPPA-based PET im- }}$ ages according to the noise, Wiener filter, median filter, and TV algorithm, respectively. For the visual evaluation, the PET images with Wiener and median filters as conventional noise-reduction methods assessed the blurring effect in the MR-AC Dixon-CAIPI- $_{\text {and }}$

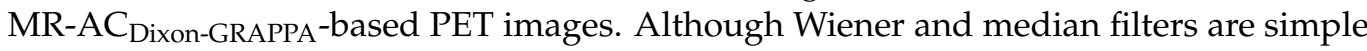
methods to reduce the noise distribution in the spatial domain, there are disadvantages of removing detailed regions and loss of edge signals. However, PET images with a TV algorithm based on a regularization term for noise reduction can distinguish each rod better than conventional filters.

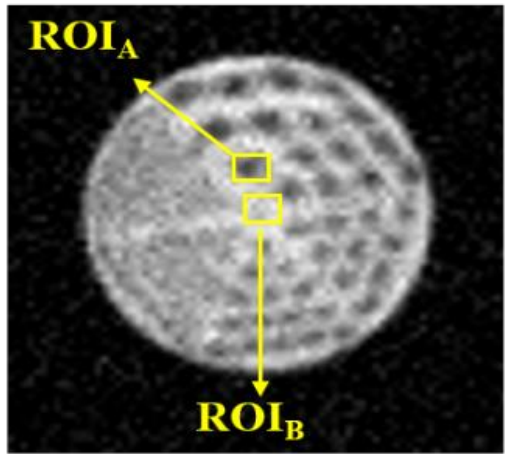

(a)

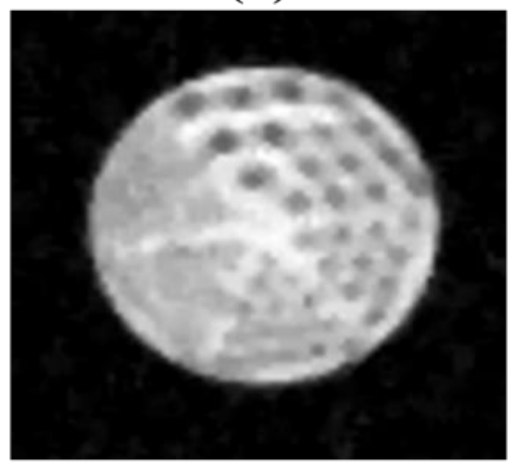

(c)

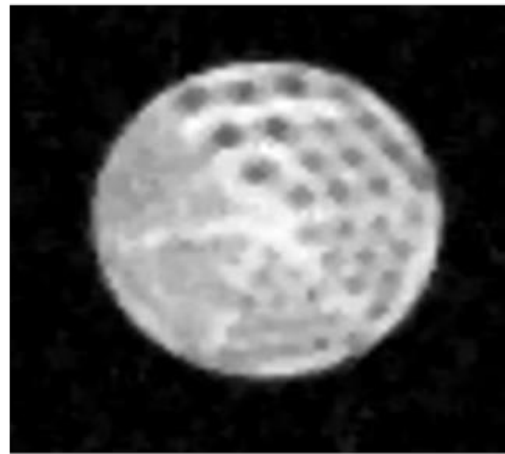

(b)

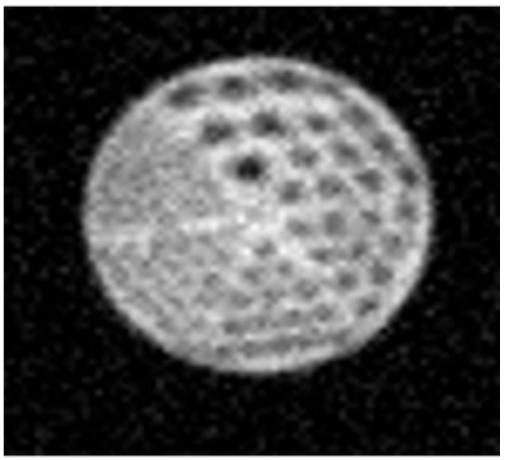

(d)

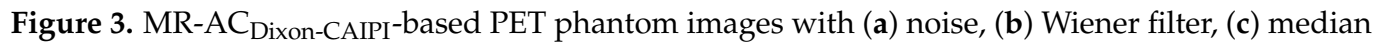
filter, and (d) TV algorithm. The contrast-to-noise ratio (CNR) was calculated using the $\mathrm{ROI}_{\mathrm{A}}$ and $\mathrm{ROI}_{\mathrm{B}}$, and the coefficient of variation (COV) was calculated using the $\mathrm{ROI}_{\mathrm{A}}$. 


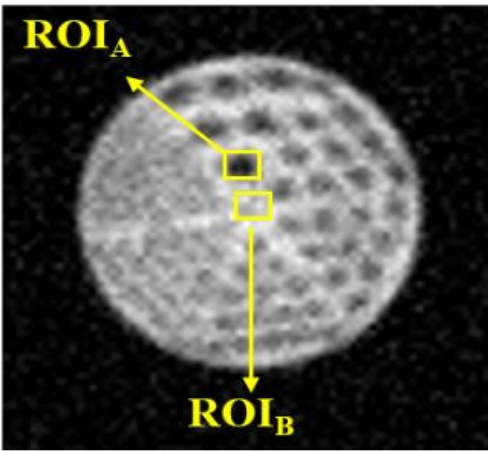

(a)

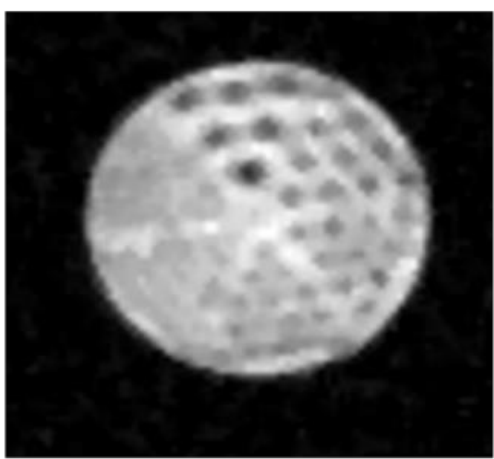

(c)

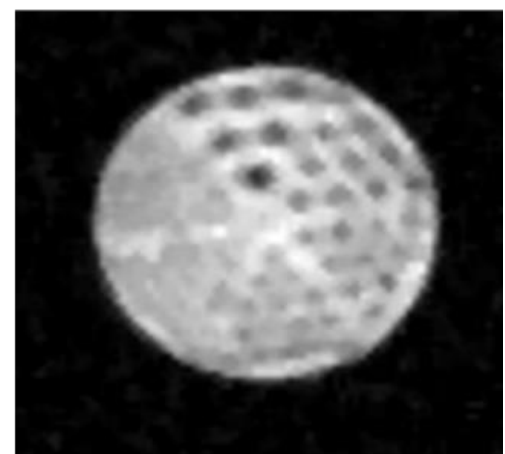

(b)

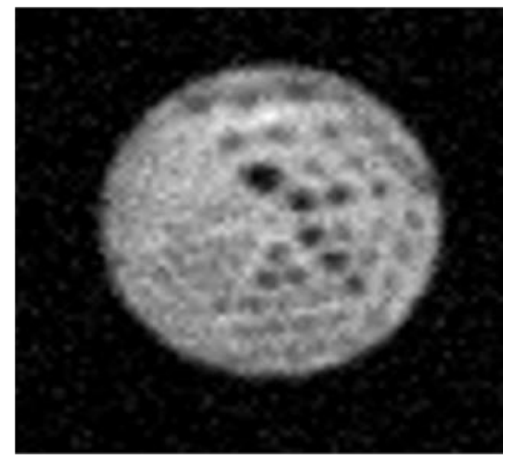

(d)

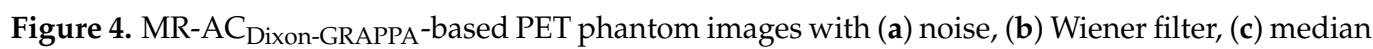
filter, and (d) TV algorithm. The contrast-to-noise ratio (CNR) was calculated using the $\mathrm{ROI}_{\mathrm{A}}$ and $\mathrm{ROI}_{\mathrm{B}}$, and the coefficient of variation $(\mathrm{COV})$ was calculated using the $\mathrm{ROI}_{\mathrm{A}}$.

The CNR and COV results are shown in Figures 5 and 6, respectively. When the MR-

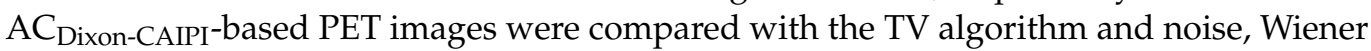
filter, and median filter regarding the CNR, the PET images with the TV algorithm showed values that were approximately $23.0 \%, 12.3 \%$, and $9.1 \%$ higher than those with noise, Wiener filter, and median filter, respectively. When the MR-AC $C_{\text {Dixon-GRAPPA-based PET }}$ images were compared with the TV algorithm and noise, Wiener filter, and median filter with respect to the CNR result, the PET image with the TV algorithm showed values that were approximately $15.8 \%$ and $8.7 \%$ higher than images with noise and the Wiener filter, respectively. When comparing the images with the TV algorithm and median filter, there was no significant difference with respect to the CNR results in the MR-AC Dixon-GRAPPA $^{-}$

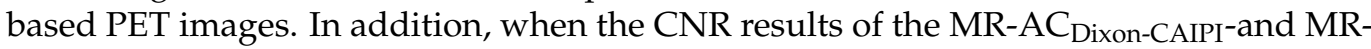
$\mathrm{AC}_{\text {Dixon-GRAPPA-based PET images were compared, the MR-AC }}$ Dixon-CAIPI-based PET images showed values that were approximately $8.2 \%, 3.1 \%$, and $11.8 \%$ higher than that of PET images with the Wiener filter, median filter, and TV algorithm, respectively. In summary,

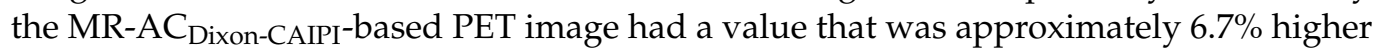

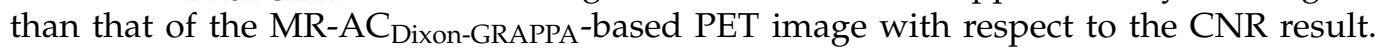

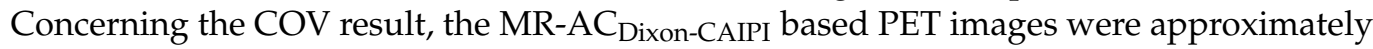
$27.9 \%$ and $23.8 \%$ lower than images with noise and Wiener filter, respectively. In addition,

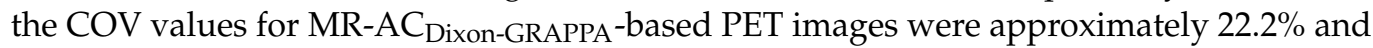
$16.7 \%$ lower than images with noise and Wiener filter, respectively. There was no significant difference with respect to the MR-AC $\mathrm{Dixn}_{\text {Dixon-CAIPI-and }} \mathrm{MR}-\mathrm{AC} \mathrm{C}_{\text {Dixon-GRAPPA }}$-based PET images and the COV results between the median filter and TV algorithm. When the MR-

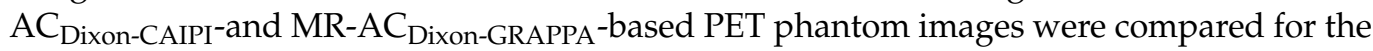
COV results, the MR-AC $C_{\text {Dixon-CAIPI }}$ based PET images had values that were approximately $50.6 \%, 50.0 \%, 54.3 \%$, and 54.3\% lower than images with noise, Wiener filter, median filter, and TV algorithm, respectively. In summary, the COV value of the MR-AC Dixon-CAIPI-based $_{\text {- }}$ 
PET image was approximately $52.3 \%$ lower than that of the MR-AC Dixon-GRAPPA $_{\text {-based }}$ PET phantom image.

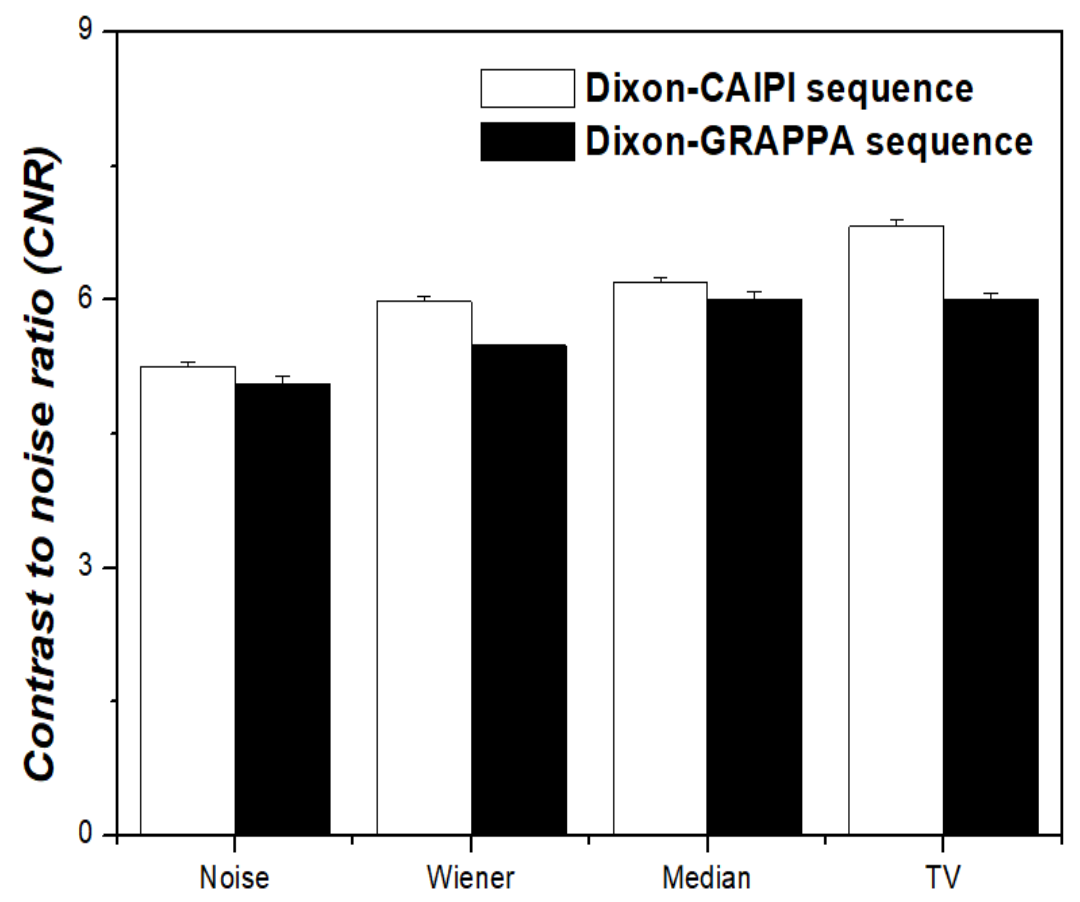

Figure 5. Contrast-to-noise ratio (CNR) according to noise-reduction techniques between MR$\mathrm{AC}_{\text {Dixon-CAIPI }}$-based and MR-AC Dixon-GRAPPA $_{\text {-based PET images. }}$

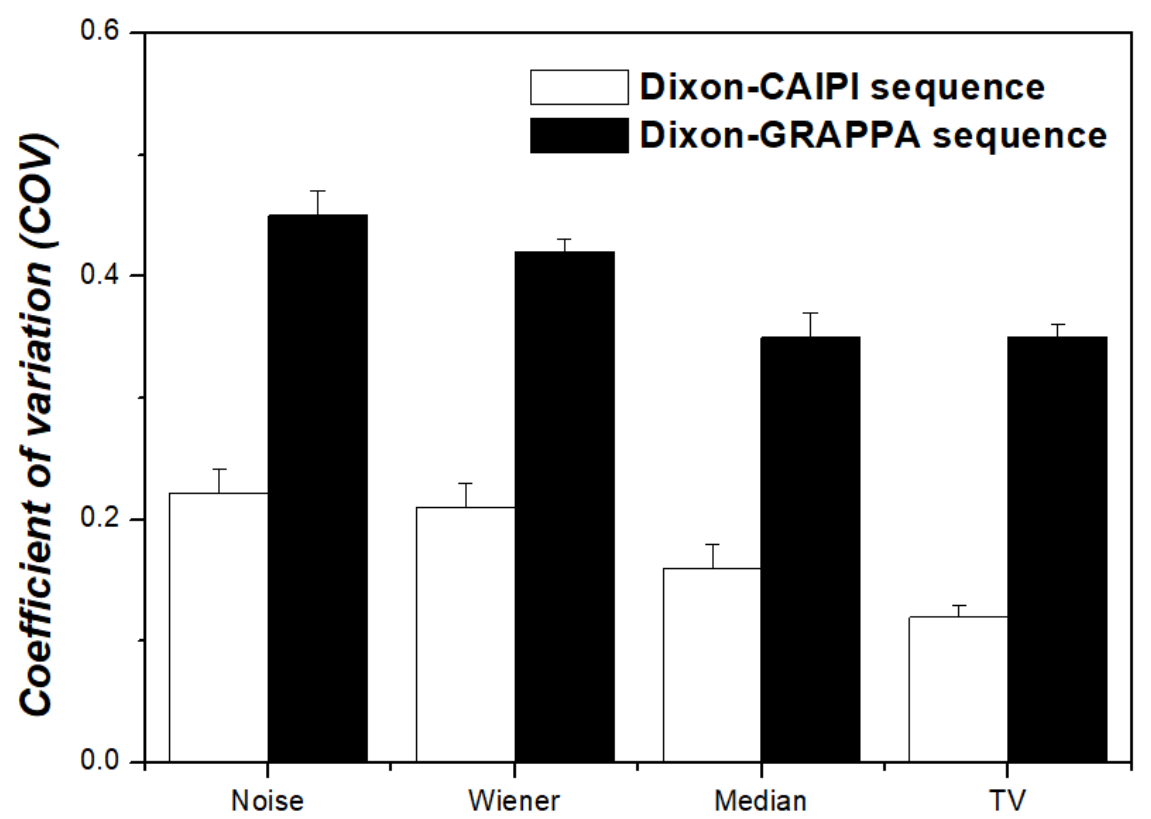

Figure 6. Coefficient of variation (COV) according to noise-reduction techniques between MR$\mathrm{AC}_{\text {Dixon-CAIPI }}$-based and MR-AC Dixon-GRAPPA $_{\text {-based PET images. }}$

In clinical PET/MR, the time for image acquisition is related to image quality. The narrow bore size $(\sim 60 \mathrm{~cm})$ compared with that of PET $/ \mathrm{CT}(\sim 70 \mathrm{~cm})$ leads to motion artifacts and is uncomfortable for patients. In general, PET/MR acquisition time is longer than that of PET/CT due to a scan procedure of only a PET image, MR-AC pulse sequences, and then only an MR image. Among these procedures, the MR-AC pulse sequence can control 
the acquisition time using various sequences. The MR-AC $\mathrm{C}_{\text {Dixon-CAIPI }}$ pulse sequence which takes a short time for acquisition, is an important factor, because a long acquisition time can affect artifacts in a PET/MR breath-hold scan. Therefore, the MR-AC Dixon-CAIPI pulse sequence is more useful than the MR-AC $C_{\text {Dixon-GRAPPA }}$ pulse sequence in terms of time resolution. In addition, the fusion images from PET and MR were used to evaluate functional and anatomy information using various MR pulse sequences for patients. Compared with MR CAIPI and GRAPPA pulse sequences in the clinical images, when the MR CAIPI pulse sequence was used, the image quality was improved, according to Wright K. L. et al. [38].

Research on the improvement of image quality in PET/MR has been previously performed for attenuation correction based on MR pulse sequences. Grafe et al. indicated that an improved MR-AC pulse sequence that is divided into five compartments (background, fat, lungs, soft tissue, and bone) can improve image quality by adding bone segmentation, compared with the conventional attenuation correction method [39]. In addition, we need to apply the noise-reduction algorithm, which is broadly applied to reduce noise in medical images. In this study, we confirmed the efficiency of the TV algorithm for noise reduction in PET/MR images. The application of the noise-reduction algorithm can offer accurate diagnostic information, except for unnecessary radiation exposure. Therefore, the noisereduction algorithm and MR-AC pulse sequence are essential processes for improving the PET/MR image quality. Based on our results, the application of the noise-reduction algorithm can offer accurate diagnostic information while preventing unnecessary radiation exposure and patient discomfort.

In addition, we plan to follow up on two aspects in future studies. First, we plan to compare the image quality using various noise-reduction algorithms such as the median modified Wiener filter, the fast nonlocal means algorithm, and deep-learning techniques in nuclear medicine images. Second, we will attempt to evaluate image performance in PET/MR according to fluid material in the Jaszczak phantom, such as $\mathrm{NiSO}_{4}+\mathrm{NaCl}$ and only $\mathrm{NiSO}_{4}$, instead of water, which is widely used to perform the phantom experiment using the Jaszczak phantom with the gamma camera or PET/computed tomography. Because water interferes with the generation of MR-AC PET images, the new fluid material should be used for the acquisition of MR-AC PET images. For this reason, Ziegler et al. reported that the use of an alternative fluid material, such as $\mathrm{NiSO}_{4}+\mathrm{NaCl}$ or only $\mathrm{NiSO}_{4}$, can lead to obtaining MR-AC PET images [40]. In addition, Park et al. suggested that $\mathrm{NaCl}$ fluid is as effective as $\mathrm{NiSO}_{4}+\mathrm{NaCl}$ fluid, without obstructing MR-AC PET images [41].

\section{Conclusions}

In this study, we confirmed the effectiveness of the TV algorithm for noise reduction

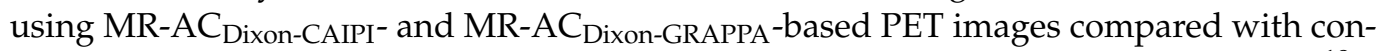
ventional noise-reduction methods in PET/MR using the Jaszczak phantom with the ${ }^{18} \mathrm{~F}$ radioisotope in an integrated $\mathrm{PET} / \mathrm{MR}$ scanner. The CNR and COV results demonstrated that the application of the TV algorithm was capable of improving the PET image quality. In conclusion, the TV algorithm is applicable to MR pulse sequence-based PET images in $\mathrm{PET} / \mathrm{MR}$ with respect to noise reduction, especially MR-AC $\mathrm{Dix}_{\text {Dix-CAIPI-based PET images, }}$ which are acceptable using the TV noise-reduction algorithm.

Author Contributions: Conceptualization, C.-R.P. and Y.-J.L.; methodology, C.-R.P.; software, S.-H.K.; formal analysis, C.-R.P. and Y.-J.L.; investigation, S.-H.K.; writing-original draft preparation, C.-R.P.; writing-review and editing, S.-H.K. and Y.-J.L.; funding acquisition, C.-R.P. All authors have read and agreed to the published version of the manuscript.

Funding: This research was supported by a research grant from Jeonju University in 2020.

Institutional Review Board Statement: Not applicable.

Informed Consent Statement: Not applicable.

Data Availability Statement: Not applicable.

Conflicts of Interest: The authors declare no conflict of interest. 


\section{References}

1. Czemin, J.; Allen-Auebach, M.; Schelbert, H. Imprvements in cancer staging with PET/CT: Literature-based evidence as of September 2006. J. Nucl. Med. 2007, 48 (Suppl. 1), 78S-88S.

2. Nehmeh, S.A.; Erdi, Y.E.; Pan, T.; Pevsner, A.; Rosenzweig, K.E.; Mageras, G.S.; Schoder, H.; Vernon, P.; Squire, O.; Mostafavi, H.; et al. Four-dimensional (4D) PET/CT imaging of the thorax. Med. Phys. 2004, 31, 3179-3186. [CrossRef]

3. Shao, Y.; Cherry, S.R.; Farahani, K.; Meadors, K.; Siegel, S.; Silberman, R.W.; Marsden, P.K. Simultaneous PET and MR imaging. Phys. Med. Biol. 1997, 42, 1965-1970. [CrossRef]

4. Zaidi, H.; Montandon, M.L.; Slosman, D.O. Magnetic resonance imaging-guided attenuation and scatter corrections in threedimensional brain positron emission tomography. Med. Phys. 2003, 30, 937-948. [CrossRef]

5. Zaida, H.; Ojha, N.; Morich, M.; Griesmer, J.; Hu, Z.; Maniawski, P.; Ratib, O.; Izquierdo-Garcia, D.; Fayad, Z.A.; Shao, L. Design and performance evaluation of a whole-body Ingenuity TF PET-MRI system. Phys. Med. Biol. 2011, 56, 3091-3106. [CrossRef] [PubMed]

6. Vandenberghe, S.; Marsden, P.K. PET-MRI: A review of challenges and solutions in the development of integrated multimodality imaging. Phys. Med. Biol. 2015, 60, R115-R154. [CrossRef]

7. Kalemis, A.; Delattre, B.M.A.; Heinzer, S. Sequential whole-body PET/MR scanner: Concept, clinical use, and optimization after two years in the clinic. The manufacturer's perspective. Magn. Reson. Mater. Phys. Biol. Med. 2013, 26, 5-23. [CrossRef] [PubMed]

8. Delso, G.; Furst, S.; Jakoby, B.; Ladebeck, R.; Ganter, C.; Nekolla, S.G.; Schwaiger, M.; Ziegler, S.I. Performance measurements of the siemens mMR integrated whole-body PET/MR scanner. J. Nucl. Med. 2011, 52, 1914-1922. [CrossRef] [PubMed]

9. Delso, G.; Martinez-Moeller, A.; Bundschuh, R.A.; Ladebeck, R.; Candidus, Y.; Faul, D.; Ziegler, S.I. Evaluation of the attenuation properties of MR equipment for its use in a whole-body PET/MR scanner. Phys. Med. Biol. 2010, 55, 4361-4374. [CrossRef]

10. Torigian, D.A.; Zaidi, H.; Kwee, T.C.; Saboury, B.; Udupa, J.K.; Cho, Z.H.; Alavi, A. PET/MR imaging: Technical aspects and potential clinical applications. Radiology 2013, 267, 26-44. [CrossRef]

11. Hany, T.F.; Steinert, H.C.; Goerres, G.W.; Buck, A.; von-Schulthess, G.K. PET Diagnostic Accuracy: Improvement with In-Line PET-CT system: Initial Results. Radiology 2002, 225, 575-581. [CrossRef]

12. Kinahan, P.; Hasegawa, B.; Beyer, T. X-ray-based attenuation correction for positron emission tomography scanners. Semin. Nucl. Med. 2003, 33, 166-179. [CrossRef]

13. Burger, C.; Goerres, G.; Schoenes, S.; Buck, A.; Lonn, A.H.; Von-Schulthess, G.K. PET attenuation coefficients from CT images: Experimental evaluation of the transformation of CT into PET 511-keV attenuation coefficients. Eur. J. Nucl. Med. Mol. Imaging 2002, 29, 922-927. [CrossRef]

14. Ronal, G.; Nan, Z.; James, S.; Matthias, L.; Ralf, V.; Markus, V.; Günter, S.; Wolfgang, R.; Hubertus, F. APD-based PET detector for simultaneous PET/MR imaging. Nucl. Instrum. Methods Phys. Res. Sect. A 2006, 569, 301-305.

15. Hofmann, M.; Pichler, B.; Schölkopf, B.; Beyer, T. Towards quantitative PET/MRI: A review of MR-based attenuation correction tecniques. Eur. J. Nucl. Med. Mol. Imaging 2009, 36, S93-S104. [CrossRef] [PubMed]

16. Griswold, M.A.; Jakob, P.M.; Heidemann, R.M.; Nittka, M.; Jellus, V.; Wang, J.; Kiefer, B.; Hasse, A. Generalized autocalibrating partially parallel acquisitions (GRAPPA). Magn. Reson. Med. 2002, 47, 1202-1210. [CrossRef] [PubMed]

17. Berker, Y.; Franke, J.; Salomon, A.; Palmowski, M.; Donker, H.C.W.; Temur, Y.; Mottaghy, F.M.; Kuhl, C.; Garcia, D.I.; Garcia, Z.A.; et al. MRI-based attenuation correction for hybrid PET/MRI system: A 4-class tissue segmentation technique using a combined ultrashort-echo-time/Dixon MRI sequence. J. Nucl. Med. 2012, 53, 796-804. [CrossRef] [PubMed]

18. Breuer, F.A.; Blaimer, M.; Heidemann, R.M.; Mueller, M.F.; Griswold, M.A.; Jakob, P.M. Controlled aliasing in parallel imaging results in higher acceleration (CAIPIRINHA) for multi-slice imaging. Magn. Reson. Med. 2005, 53, 684-691. [CrossRef]

19. Breuer, F.A.; Blaimer, M.; Mueller, M.F.; Seiberlich, N.; Heidemann, R.M.; Griswold, M.A.; Jakob, P.M. Controlled aliasing in volumetric parallel imaging (2D CAIPIRINHA). Magn. Reson. Med. 2006, 55, 549-556. [CrossRef]

20. Hoffman, M.; Steinke, F.; Scheel, V.; Charpiat, G.; Farquhar, J.; Aschoff, P.; Brady, M.; Schölkopf, B.; Pichler, B.J. MRI-based attenuation correction for PET/MRI: A novel approach combining pattern recognition and atlas registration. J. Nucl. Med. 2008, 49, 1875-1883. [CrossRef]

21. Park, C.R.; Lee, Y. Fast non-local means noise reduction algorithm with acceleration function for improvement of image quality in gamma camera system: A phantom study. Nucl. Eng. Technol. 2019, 51, 719-722. [CrossRef]

22. Kim, S.H.; Seo, K.; Kang, S.; Bae, S.; Kwak, H.J.; Hong, J.W.; Hwang, Y.; Kang, S.M.; Choi, H.R.; Kim, G.Y.; et al. Study on Feasibility for Artificial Intelligence (AI) Noise Reduction Algorithm with Various Parameters in Pediatric Abdominal Radio-Magnetic Computed Tomography (CT). J. Magn. 2017, 22, 1-9. [CrossRef]

23. Goldstein, J.; Reed, I.; Scharf, L. A multistage representation of the Wiener filter based on orthogonal projections. IEEE Trans. Inf. Theory 1998, 44, 2943-2959. [CrossRef]

24. Garnier, S.J.; Bilbro, G.L.; Snyder, W.E.; Gault, J.W. Noise removal from multiple MRI images. J. Digit. Imaging 1994, 7, 183-188. [CrossRef] [PubMed]

25. Padmavathi, G.; Subashini, P.; Kumar, M.M.; Thakur, S.K. Performance analysis of non linear filtering algorithms for underwater images. Int. J. Comput. Sci. Inf. Secur. 2009, 6, 232-238.

26. Kwak, H.J.; Lee, S.J.; Lee, Y.; Lee, D.H. Quantitative study of total variation (TV) noise reduction algorithm with chest X-ray imaging. J. Instrum. 2018, 13, T01006. [CrossRef] 
27. Kang, S.; Kim, K.Y.; Hwang, Y.; Jong, J.W.; Baek, S.R.; Lee, C.; Lee, Y. A Monte Carlo simulation study for feasibility of total variation (TV) noise reduction technique using digital mouse whole body (MOBY) phantom image. Optik 2018, 156, 197-203. [CrossRef]

28. Rudin, L.I.; Osher, S.; Fatemi, E. Nonlinear total variation based noise removal algorithms. Phys. D 1992, 60, 259-268. [CrossRef]

29. Seo, K.; Kim, S.; Kang, S.; Park, J.; Lee, C.; Lee, Y. The effects of Total Variation (TV) Technique for Noise Reduction in Radio-Magnetic X-ray image. J. Magn. 2016, 21, 593-598. [CrossRef]

30. Kim, H.; Kang, S.; Kim, K.; Lee, Y. Total Variation-Based Noise Reduction Image Processing Algorithm for Confocal Laser Scanning Microscopy Applied to Activity Assessment of Early Carious Lesions. Appl. Sci. 2020, 10, 4090. [CrossRef]

31. Bernstein, M.A.; Huston III, J.; Ward, H.A. Imaging Artifacts at 3.0T. J. Magn. Reson. Imaging 2006, 24, 735-746. [CrossRef] [PubMed]

32. Beck, A.; Teboulle, M. Fast gradient-based algorithms for constrained total variation image denoising and deblurring problems. IEEE Trans. Image Process. 2009, 18, 2419-2434. [CrossRef] [PubMed]

33. Kang, S.H.; Yoon, M.S.; Han, D.K.; Lee, Y. Total variation noise reduction algorithm in computed tomography image with custom-built phantom using 3D-printer. Radiat. Phys. Chem. 2020, 170, 108631. [CrossRef]

34. Zaharchuk, G. Next generation research applications for hybrid PET/MR and PET/CT imaging using deep learning. Eur. J. Nucl. Med. Mol. Imaging 2019, 46, 2700-2707. [CrossRef] [PubMed]

35. Yang, X.; Wang, T.; Lei, Y.; Higgins, K.; Liu, T.; Shim, H.; Curran, W.J.; Mao, H.; Nye, J.A. MRI-based attenuation correction for brain PET/MRI based on anatomic signature and machine learning. Phys. Med. Biol. 2019, 64, 025001. [CrossRef]

36. Sidky, E.Y.; Duchin, Y.; Ullberg, C.; Pan, X. A constrained, total-variation minimization algorithm for low-intensity x-ray CT. Med. Phys. 2011, 38, S117-S125.

37. Lee, S.; Lee, Y. Performance evaluation of total variation (TV) denoising technique for dual energy contrast-enhanced digital mammography (CEDM) with photon counting detector (PCD): Monte Carlo simulation study. Radiat. Phys. Chem. 2019, 156, 94-100. [CrossRef]

38. Wright, K.L.; Harrell, M.W.; Jesberger, B.S.; Landeras, L.; Nakamoto, D.A.; Thomas, S.; Nickel, D.; Kroeker, R.; Griswold, M.A.; Gulani, V. Clinical evaluation of CAIPIRINHA: Comparison against a GRAPPA standard. J. Magn. Reson. Imaging 2014, 39, 189-194. [CrossRef]

39. Grafe, H.; Lindemann, M.E.; Ruhlmann, V.; Oehmigen, M.; Hirmas, N.; Umutlu, L.; Herrmann, K.; Quick, H.H. Evaluation of improved attenuation correction in whole-body PET/MR on patients with bone metastasis using various radiotracers. Eur. J. Nucl. Med. Mol. Imaging 2020, 47, 2269-2279. [CrossRef]

40. Ziegler, S.; Braun, H.; Ritt, P.; Hocke, C.; Kuwert, T.; Quck, H.H. Systemic evaluation of phantom fluids for simultaneous PET/MR hybrid imaging. J. Nucl. Med. 2013, 54, 1464-1471. [CrossRef]

41. Park, C.R.; Kim, K.; Lee, Y. Development of a bias field-based uniformity correction in magnetic resonance imaging with various standard pulse sequences. Optik 2018, 178, 161-166. [CrossRef] 